\title{
The role of rotation thromboelastometry in early prediction of massive transfusion
}

\author{
Leemann, H ; Lustenberger, T ; Talving, P ; Kobayashi, L ; Bukur, M ; Brenni, M ; Brüesch, M ;
} Spahn, D R ; Keel, M J B

\begin{abstract}
INTRODUCTION:: Early prediction of massive transfusion (MT) is critical in the management of severely injured trauma patients. Variables available early after injury including physiologic, laboratory, and rotation thromboelastometric (ROTEM) parameters were evaluated as predictors for the need of MT. METHODS:: After Institutional Review Board approval, we retrospectively reviewed a cohort of severely injured trauma patients (Injury Severity Score 16) admitted to a Level I trauma center with available ROTEM measurements on hospital admission during a 1-year study period. Patients with isolated head injury (Abbreviated Injury Scale head 3 and Abbreviated Injury Scale chest, abdomen, and extremity $<3$ ) and patients with a penetrating mechanism of injury were excluded. Patients who received a MT ( 10 units packed red blood cell within 24 hours of admission) were compared with patients who did not. Variables independently associated with MT were identified using stepwise logistic regression. RESULTS:: A total of 53 patients met inclusion criteria. Of these, 18 patients (34.0\%) received a MT and 35 patients $(66.0 \%)$ did not. Massively transfused patients had significantly lower baseline hemoglobin values (7.9 $\mathrm{g} / \mathrm{dL} \pm 0.4 \mathrm{~g} / \mathrm{dL}$ vs. $11.4 \mathrm{~g} / \mathrm{dL} \pm 0.4 \mathrm{~g} / \mathrm{dL} ; \mathrm{p}<0.001)$ and a trend toward higher lactate $(4.8 \mathrm{mmol} / \mathrm{L} \pm$ $0.8 \mathrm{mmol} / \mathrm{L}$ vs. $3.0 \mathrm{mmol} / \mathrm{L} \pm 0.3 \mathrm{mmol} / \mathrm{L} ; \mathrm{p}=0.056)$ and base deficit values $(5.9 \mathrm{mmol} / \mathrm{L} \pm 1.1 \mathrm{mmol} / \mathrm{L}$ vs. $3.6 \mathrm{mmol} / \mathrm{L} \pm 0.6 \mathrm{mmol} / \mathrm{L} ; \mathrm{p}=0.052)$. Mean international normalized ratio $(1.46 \pm 0.07$ vs. 1.22 $\pm 0.05 ; \mathrm{p}=0.001)$ and partial thromboplastin times $(42.4$ seconds \pm 5.0 seconds vs. 29.7 seconds \pm 1.8 seconds; $\mathrm{p}<0.001$ ) were significantly higher in MT patients. Patients receiving a MT had significantly altered ROTEM values on admission compared with non-MT patients. An increase in the clot formation time (471.3 seconds \pm 169.9 seconds vs. 178.1 seconds \pm 19.9 seconds; $p=0.001$ ), a shortening of the maximum clot firmness $(37.5 \mathrm{~mm} \pm 2.9 \mathrm{~mm}$ vs. $50.7 \mathrm{~mm} \pm 1.4 \mathrm{~mm}$; $<<0.001)$, and a shortening of the clot amplitude at all time points (10/20/30 minutes) were observed in massively transfused trauma patients. Variables independently associated with MT included a hemoglobin level $10 \mathrm{~g} / \mathrm{dL}$ and an abnormal maximum clot firmness value (area under the receiver operator characteristic curve: 0.831 [95\% confidence interval: 0.719-0.942; $\mathrm{p}<0.001]$ ). CONCLUSION:: Hemoglobin $10 \mathrm{~g} / \mathrm{dL}$ and an abnormal maximum cloth firmness measured by rotation thromboelastometry on admission reliably predict the need for MT. Prospective validation of the effectiveness of thromboelastometry to guide the transfusion practice after trauma is warranted.
\end{abstract}

DOI: https://doi.org/10.1097/TA.0b013e3181faaa25

Posted at the Zurich Open Repository and Archive, University of Zurich

ZORA URL: https://doi.org/10.5167/uzh-40801

Journal Article

Accepted Version 
Originally published at:

Leemann, H; Lustenberger, T; Talving, P; Kobayashi, L; Bukur, M; Brenni, M; Brüesch, M; Spahn, D R; Keel, M J B (2010). The role of rotation thromboelastometry in early prediction of massive transfusion. Journal of Trauma - Injury Infection Critical Care, 69(6):1403-1409.

DOI: https://doi.org/10.1097/TA.0b013e3181faaa25 


\section{ABSTRACT}

Introduction: Early prediction of massive transfusion (MT) is critical in the management of severely injured trauma patients. Variables available early after injury including physiologic, laboratory and rotation thromboelastometric $\left(\right.$ ROTEM $\left.^{\circledR}\right)$ parameters were evaluated as predictors for the need of MT.

Methods: After IRB approval, we retrospectively reviewed a cohort of severely injured trauma patients (ISS $\geq 16$ ) admitted to a level 1 trauma center with available ROTEM ${ }^{\circledR}$ measurements on hospital admission during a 1-year study period. Patients with isolated head injury [Abbreviated Injury Scale (AIS) head $\geq 3$ and AIS chest, abdomen, and extremity <3] and patients with a penetrating mechanism of injury were excluded. Patients who received a MT ( $\geq 10$ units PRBC within 24 hours of admission) were compared with patients who did not. Variables independently associated with MT were identified using stepwise logistic regression.

Results: A total of 53 patients met inclusion criteria. Of these, 18 patients $(34.0 \%)$ received a MT and 35 patients $(66.0 \%)$ did not. Massively transfused patients had significantly lower baseline hemoglobin values $(7.9 \pm 0.4$ vs. $11.4 \pm 0.4 \mathrm{~g} / \mathrm{dL} ; p<0.001)$ and a trend towards higher lactate $(4.8 \pm 0.8$ vs. $3.0 \pm 0.3 \mathrm{mmol} / \mathrm{L} ; p=0.056)$ and base deficit values $(5.9 \pm 1.1$ vs. $3.6 \pm 0.6 \mathrm{mmol} / \mathrm{L} ; p=0.052)$. Mean INR ( $1.46 \pm 0.07$ vs. 1.22 $\pm 0.05 ; p=0.001)$ and partial thromboplastin times ( $42.4 \pm 5.0$ vs. $29.7 \pm 1.8 \mathrm{sec} ; p<0.001)$ were significantly higher in MT patients. Patients receiving a MT had significantly altered ROTEM ${ }^{\circledR}$ values on admission compared to non-MT patients. An increase in the clot formation time $(471.3 \pm 169.9$ vs. $178.1 \pm 19.9 \mathrm{sec} ; p=0.001)$, a shortening of the 
maximum clot firmness $(37.5 \pm 2.9$ vs. $50.7 \pm 1.4 \mathrm{~mm} ; p<0.001)$, and a shortening of the clot amplitude at all time-points (10/20/30 minutes) were observed in massively transfused trauma patients. Variables independently associated with MT included a hemoglobin level $\leq 10 \mathrm{~g} / \mathrm{dL}$ and an abnormal maximum clot firmness value [area under the ROC curve: 0.831 (95\% CI: $0.719-0.942 ; p<0.001)]$.

Conclusion: Hemoglobin $\leq 10 \mathrm{~g} / \mathrm{dL}$ and an abnormal maximum cloth firmness measured by rotation thromboelastometry on admission reliably predict the need for massive transfusion. Prospective validation of the effectiveness of thromboelastometry to guide the transfusion practice following trauma is warranted.

Key words: massive transfusion, thromboelastometry, ROTEM ${ }^{\circledR}$, thromboelastography, $T E G^{\circledR}$, predictor 


\section{The Role of Rotation Thromboelastometry in Early Prediction of Massive Transfusion}

Harald Leemann ${ }^{1}$, MD; Thomas Lustenberger ${ }^{2}, \mathrm{MD}$; Peep Talving ${ }^{2}$, MD, PhD, FACS; Leslie Kobayashi ${ }^{2}$, MD; Marko Bukur ${ }^{2}$, MD; Mirko Brenni ${ }^{3}$, MD; Martin Brüesch ${ }^{4}$, MD; Donat R. Spahn ${ }^{4}$, MD; Marius Johann Baptist Keel ${ }^{5}$, MD

${ }^{1}$ Division of Surgery, Hospital Zug, Zug, Switzerland

${ }^{2}$ Keck School of Medicine, Department of Surgery, Division of Acute Care Surgery (Trauma, Emergency Surgery, and Surgical Critical Care), Department of Surgery, $-\underline{\text { Keck }}$ School of Medicine, Los Angeles County + University of Southern California Medical Center, Los Angeles, CA

${ }^{3}$ Department of Anesthesiology, Lindberg Hospital, Winterthur, Switzerland

${ }^{4}$ Department of Anesthesiology, University Hospital of Zurich, Zurich, Switzerland

${ }^{5}$ Department of Orthopaedic Surgery, Inselspital, University of Bern, Bern, Switzerland

\section{Corresponding author:}

Thomas Lustenberger, MD

University of Southern California - Keck School of Medicine

Department of Surgery - Division of Acute Care Surgery

(Trauma, Emergency Surgery \& Surgical Critical Care)

Los Angeles County General Hospital (LAC + USC)

1200 North State Street, C5L100

Los Angeles, CA, 90033 - 4525

Tel: 3234098594

Fax: 3234419909

Email: tom.lustenberg@gmail.com 


\section{INTRODUCTION}

\section{MassiveTraumatic hemorrhage following injury results in coagulopathy, which}

subsequently leads to further blood loss. Several mechanisms including tissue injury, hemodilution, hypothermia, acidosis, and inflammation are postulated to be the main eauses ofpredispose for traumatic coagulopathy. ${ }^{1-3}$ A recent report by Brohi and colleagues ${ }^{4}$, however, suggested an alternative coagulopathy pathway following major trauma independent of clotting-factor deficiency.-Early traumatic coagulopathy occurred exclusively in the setting of tissue hypoperfusion resulting in activation of the thrombomodulin protein C system, higher tPA levels, and fibrinolysis._While further investigations to fully comprehend pathways of acute coagulopathy are warranted, coagulation abnormalities have been demonstrated to be associated with poor outcomes. ${ }^{1 \text {, }}$ ${ }^{5,6}$ Additionally, it has been observed that coagulopathy occurring in the early posttraumatic phase correlates closely with massive transfusion (MT) requirement. ${ }^{1,5,7}$ After increasing number of studies demonstrating improved outcomes pertinent due to agressive plasma and platelet replacements in patients requiring $\mathrm{MT}^{8-10}$, many trauma centers have instituted massive transfusion protocols. ${ }^{11-15}$ Most MT protocols, however, are triggered by physicianss only after when elinical suspicion of a significantlarge blood loss is imminent, or-when transfusion of massive amounts of packed red cells has already

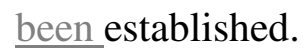

Therefore, Sseveral scoring systems have recently been proposed to predict the need for MT. ${ }^{16-21}$ However, the vast majority of suchggested algorithms require time-consuming laboratory work-up, injury severity calculations, or mathematical computations.

Relatively scantlittle is the documentationed pertinent to-about point-of-care devices, 
such as thromboelastogaphy $\left(\mathrm{TEG}^{\circledR}\right)$ and rotation thromboelastometry $\left(\mathrm{ROTEM}^{\circledR}\right)$, as predictors of transfusion requirement after injury. ${ }^{22-24}-$ TEG $^{\circledR}$ and ROTEM ${ }^{\circledR}$ may overcome several limitations of routine coagulation tests and may further provide useful information on platelet function. ${ }^{25-27}$ Subsequent transfusion algorithms based on pointof-care assays have been promising resulting in reduced transfusion requirements in $\operatorname{cardiac}^{28,29}$ and hepatic ${ }^{30,31}$ surgery.

The purpose of the present study was to determine the role of ROTEM $^{\circledR}$ as the predictor of MT following trauma. In addition to the ROTEM $^{\circledR}$ values, physiologic and laboratory variables readily available early after injury were also evaluated as predictors of MT. 


\section{METHODS}

After approval by the Institutional Review Board, we retrospectively reviewed a cohort of severely injured trauma patients admitted to the Division of Trauma Surgery of the University Hospital of Zurich, a referral trauma center, from January through December 2006. The inclusion criteria were an Injury Severity Score (ISS) $>16$ and available ROTEM ${ }^{\circledR}$ measurements on hospital admission. Patients with isolated head injury [Abbreviated Injury Scale (AIS) head $\geq 3$ and AIS chest, abdomen, and extremity <3] $(\mathrm{n}=48)$ and patients with a penetrating mechanism of injury $(\mathrm{n}=19)$ were excluded. A MT was defined as a transfusion of 10 or more packed red blood cell (PRBC) units during the initial 24 hours after admission.

Demographic and clinical information collected included age, gender, blood pressure on admission, Glasgow Coma Scale (GCS) score on admission, ISS, and AIS for each body region (head, chest, abdomen, extremity). Continuous variables were converted into dichotomous variables using clinically relevant cut-points (age $\geq 55$ years, systolic blood pressure $<90 \mathrm{mmHg}, \mathrm{GCS} \leq 8, \mathrm{ISS} \geq 25$, AIS $\geq 3$ ). All hemoglobin values, base deficit, lactate, $\mathrm{pH}$ values, platelet counts, international normalized ratio (INR) values, and partial thromboplastin times (PTT) obtained on admission were also accrued. The number of PRBC, fresh frozen plasma (FFP), and platelet units transfused were abstracted.

\section{Point-of-care Devices}

$\mathrm{TEG}^{\circledR}$ and $\mathrm{ROTEM}^{\circledR}$ provide a real-time graphic assessment of clot formation and subsequent lysis. Blood is incubated at $37^{\circ} \mathrm{C}$ in a heated cup. Within this cup is 
suspended a pin connected to a detector system. This is a torsion wire in case of TEG ${ }^{\circledR}$ and an optical detector in $\mathrm{ROTEM}^{\circledR}$. The cup and pin are oscillated relative to each other. The movement is initiated from either the cup $\left(\mathrm{TEG}^{\circledR}\right)$ or the pin $\left(\mathrm{ROTEM}^{\circledR}\right)$. As fibrin forms between the cup and pin the transmitted rotation from the cup to pin $\left(\mathrm{TEG}^{\circledR}\right.$ ) or impedance of the rotation of the pin $\left(\right.$ ROTEM $\left.^{\circledR}\right)$ is detected at the pin and a trace is generated. $^{25}$

During the study period, rotation thromboelastometry measurements were obtained at the discretion of the attending physician in severely injured patients. Blood samples were drawn and analyzed in a ROTEM $^{\circledR}$ analyzer [Pentapharm GmbH (Munich, Germany)] within 15 minutes of admission. The ROTEM $^{\circledR}$ coagulation analyzer and the parameters of thromboelastometry have been described elsewhere. ${ }^{32}$ Briefly, ROTEM $^{\circledR}$ measurements graphically display the changes in viscoelasticity at all stages of the developing and resolving clot. In the ROTEM $^{\circledR}$ analyzer, coagulation is mildly activated either with ellagic acid (INTEM test) or tissue factor from rabbit brain (EXTEM test). Both, the INTEM as well as the EXTEM test were performed in the study cohort. The test time for $\mathrm{ROTEM}^{\circledR}$ is typically 15 to 20 minutes. ROTEM $^{\circledR}$ parameters analyzed in this study included the time until initial fibrin formation [clotting time (CT)], the kinetics of fibrin formation and clot development [clot formation time (CFT) and the alpha angle], the stability of the fibrin clot at various time-points [amplitude of the clot at 10 minutes (A10), at 20 minutes (A20), and at 30 minutes (A30)] and the ultimate strength and stability of the fibrin clot [maximum clot firmness (MCF)]. The reference ranges utilized for ROTEM ${ }^{\circledR}$ parameters were previously described by Lang and colleagues. $^{32}$ 


\section{STATISTICAL ANALYSIS}

The demographic and clinical characteristics between massively and non-massively transfused trauma patients were evaluated using bivariate analysis. Laboratory parameters including coagulation markers, base deficit, lactate and ROTEM $^{\circledR}$ parameters were also compared between the two cohorts. The $p$ values for categorical variables were derived from the Chi-square test or 2-sided Fisher's exact test and for continuous variables the Mann-Whitney test was deployed.

To identify risk factors independently associated with the need for a MT, a stepwise logistic regression was utilized and risk factors from the bivariate analysis with a $p$ value $<0.2$ were included in the model. The area under the receiver operator characteristic (ROC) curve was constructed to evaluate the model's discriminating power to predict MT.

Values are reported as mean \pm standard error of the mean (SEM) for continuous variables and as percentages for categorical variables. All analyses were performed using the Statistical Package for Social Sciences version 12.0 (SPSS Inc., Chicago, IL). 


\section{RESULTS}

During the 1-year study period, 53 patients met inclusion criteria. Of these, 18 patients (34.0\%) received a MT and 35 patients (66.0\%) did not. The average age of these patients was $39.6 \pm 2.5$ years and the mean ISS was $31.1 \pm 1.7$. Detailed demographic data, injury characteristics and major surgical procedures of the study groups are depicted in Table 1. Severe traumatic brain injury (AIS head $\geq 3$ ) was present in $64.2 \%$. The predominant intracranial injuries included intraparenchymal hematoma (28.3\%), subdural hematoma (24.5\%), subarachnoid hemorrhage (20.8\%), and epidural hematoma (17.0\%). Survival to discharge was $61 \%$ in the MT group and $66 \%$ in the non-MT group $(p=0.741)$, respectively.

Patients in the MT group received on average 22.3 \pm 3.9 units PRBC during the initial 24 hours of admission compared to $2.7 \pm 0.5$ units in the non-MT group $(p<0.001)$. Likewise, the transfusion rates of FFP $(16.4 \pm 3.0$ vs. $1.9 \pm 0.5$ units; $p<0.001)$ and platelets $(14.3 \pm 3.0$ vs. $0.8 \pm 0.4$ units; $p<0.001)$ were significantly higher in the MT group compared to their non-MT counterparts. A detailed description of the blood components utilized for resuscitationtransfused within different time frames of the initial 24 hours is provided in Table 2.

Table 3 depicts admission laboratory values comparing the MT and non-MT groupcohorts. Massively transfused patients experienced significantly lower baseline hemoglobin values and an obvious-strong trend towards higher lactate and base deficit values. Mean INR and partial thromboplastin times were significantly higher in the MT 
patients. Additionally, a trend towards lower platelet counts in the MT group was observed.

Patients receiving a MT had significantly different values in almost all ROTEM ${ }^{\circledR}$ tests on admission compared to non-MT patients (Table 4). A significant increase in the CFT, a shortening of the MCF and a shortening of the clot amplitude at all time-points (A10, A20, A30) were observed in massively transfused trauma patients (Table 4).

Bivariate analysis was performed to identify risk factors associated with the need for MT (Figure 1). The results of the stepwise logistic regression analysis are presented in Table 5. Variables independently associated with the need for MT included a hemoglobin level $\leq 10 \mathrm{~g} / \mathrm{dL}$ and an abnormal INTEM MCF value. Using these two factors as a predictive model, the area under the ROC curve was 0.831 (95\% CI: $0.719-0.942$; $p<0.001)$. Using the INTEM MCF as a single variable to predict MT revealed an area under the ROC curve of 0.824 (95\% CI: $0.708-0.941 ; p<0.001)$. 


\section{DISCUSSION}

Point-of-care devices have been utilizedsed for many years_to guide effective blood component and drug administration during major surgery. Numerous studies, the majority of those performed in patients undergoing liver ${ }^{30,31}$ or cardiac $^{28,29}$ surgery,

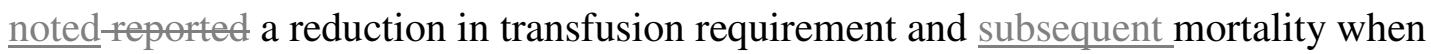
transfusion therapy was based on $\mathrm{TEG}^{\circledR} / \mathrm{ROTEM}^{\circledR}$ results as compared to therapy guided by conventional coagulation markers. Recently, in a before-after study, Johansson et al. ${ }^{33}$ reported the effect a reduction of therapy in massively bleeding patients, $21 \%$ of those being trauma patients. In this examination, Ppatients treated according to the $\mathrm{TEG}^{\circledR}$ results had a significantly lower 30-day mortality as compared to controls (20\% vs. $32 \%)$.

While the beneficial value of point-of-care devices to tailor blood component requirements-therapyduring transfusion therapy has been previously shown, the goal of the present study was to examine the role of ROTEM $^{\circledR}$ in the very early prediction of MT in trauma patientsfollowing trauma. One of the earliest attempts to evaluate the usefulness of point-of-care assays in the assessment of the coagulation status in trauma victims was performed conducted by Kaufmann et al. in $1997 .{ }^{22}$ In their study, including 69 blunt trauma patients, $65 \%$ demonstrated hypercoagulability upon hospital arrival whereas only $10 \%$ were hypocoagulable. Of the hypocoagulable patients, $86 \%$ received blood products within the first 24 hours, whereas only $4 \%$ of the hypercoagulable

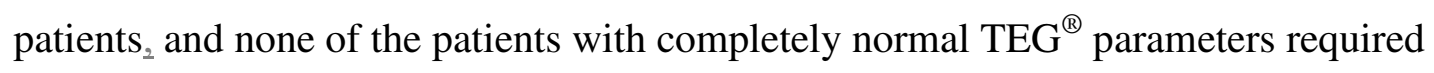
transfusion within the first 24 hours. A hypocoagulable $\mathrm{TEG}^{\circledR}$ was associated with increased ISS and only ISS and TEG ${ }^{\circledR}$ were predictive of transfusion requirements within 
the first 24 hours. Nevertheless However, the vast majority of patients in that study did not receive a MT. In patients sustaining penetrating insults, Plotkin et al. ${ }^{23}$ demonstrated that the maximum clot amplitude significantly correlated with the total amount of blood products used within the initial 24 hours. Conventional coagulation variables, such as INR, prothrombin time and partial thromboplastin time, discriminated hypo- from normo/hypercoagulopathic patients, but did not predict transfusion requirements. Likewise, in

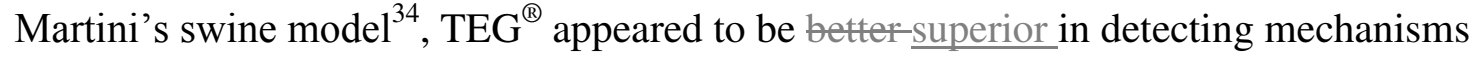
associated with coagulopathy induced by hypothermia and hemorrhage than conventional coagulation markers.

In the present examination, we evaluated several physiologic, laboratory as well as ROTEM ${ }^{\circledR}$ variables and their ability to predict the need for MT. ROTEM $^{\circledR}$ parameters on admission and, in particular the INTEM channel, discriminated significantly the massively transfused from the non-massively transfused-blunt trauma patients. Additionally, the maximum cloth firmness (INTEM MCF) in combination with a low hemoglobin value $(\leq 10 \mathrm{~g} / \mathrm{dL})$ was-proved to be independently associated with the need for MT (area under the ROC curve: 0.824 ) and is in this regard comparable to thoseagreement with models-already published in the literature. ${ }^{7,16-20}$ Both variables are promptly available in the resuscitation bay. The hemoglobin values can be measured in a point-of-care device within minutes. Likewise, ROTEM $^{\circledR}$ can be conducted rapidly in the emergency department with readily available results providing a wide range of information-data on the patient's coagulation status. ${ }^{35}$

Although this is one of the first studies examining the role of ROTEM $^{\circledR}$ in the prediction of MT, there are several limitations, the most important being the retrospective 
nature of the data analysis. Evaluation of the coagulation status was performed in severely injured patients at the discretion of the attending physician, and may therefore have resulted in a selection bias. Data on fibrinolysis, guiding transfusion practice in both ROTEM $^{36}$ and TEG studies ${ }^{24}$, was not available for the current analysis. Lastly, our study conclusions are limited by the small sample size and the wide variety of injury patterns included. Almost two thirds of our study cohort suffered severe head injuries, a patient population_in particularly prone to be at high risk for-developing coagulopathy, however, pathways of coagulation abnormalities in head injured patients are likely to be very different to those of suffering torso trauma. ${ }^{37-39}$

\section{CONCLUSION}

Hemoglobin $\leq 10 \mathrm{~g} / \mathrm{dL}$ and an abnormal maximum cloth firmness measured by rotation thromboelastometry on admission reliably predict the need for massive transfusion. Further pProspective studies to validatevalidation of the effectiveness of thromboelastometry to guide the transfusion management practice in trauma patientsfollowing trauma isare warranted. 


\section{ACKNOWLEDGMENT}

The authors (M.J.B.K. and T.L.) are indebted to Prof. Dr. H.C. Otmar Trentz for his commitment, teaching and support as director of the Division of Trauma Surgery, Department of Surgery, University Hospital Zurich in recent years. 


\section{REFERENCES}

1. Brohi K, Singh J, Heron M, Coats T. Acute traumatic coagulopathy. J Trauma. 2003;54:1127-1130.

2. Hess JR, Brohi K, Dutton RP, et al. The coagulopathy of trauma: A review of mechanisms. J Trauma. 2008;65:748-754.

3. Cosgriff N, Moore EE, Sauaia A, Kenny-Moynihan M, Burch JM, Galloway B. Predicting life-threatening coagulopathy in the massively transfused trauma patient: Hypothermia and acidoses revisited. J Trauma. 1997;42:857-61; discussion 861-2.

4. Brohi K, Cohen MJ, Ganter MT, Matthay MA, Mackersie RC, Pittet JF. Acute traumatic coagulopathy: Initiated by hypoperfusion: Modulated through the protein $\mathrm{C}$ pathway? Ann Surg. 2007;245:812-818.

5. MacLeod JB, Lynn M, McKenney MG, Cohn SM, Murtha M. Early coagulopathy predicts mortality in trauma. J Trauma. 2003;55:39-44.

6. Maegele M, Lefering R, Yucel N, et al. Early coagulopathy in multiple injury: An analysis from the german trauma registry on 8724 patients. Injury. 2007;38:298-304.

7. MacLeod J, Lynn M, McKenney MG, Jeroukhimov I, Cohn SM. Predictors of mortality in trauma patients. Am Surg. 2004;70:805-810.

8. Holcomb JB, Wade CE, Michalek JE, et al. Increased plasma and platelet to red blood cell ratios improves outcome in 466 massively transfused civilian trauma patients. Ann Surg. 2008;248:447-458.

9. Borgman MA, Spinella PC, Perkins JG, et al. The ratio of blood products transfused affects mortality in patients receiving massive transfusions at a combat support hospital. $J$ Trauma. 2007;63:805-813. 
10. Sperry JL, Ochoa JB, Gunn SR, et al. An FFP:PRBC transfusion ratio $>/=1: 1.5$ is associated with a lower risk of mortality after massive transfusion. $J$ Trauma. 2008;65:986-993.

11. Cotton BA, Au BK, Nunez TC, Gunter OL, Robertson AM, Young PP. Predefined massive transfusion protocols are associated with a reduction in organ failure and postinjury complications. J Trauma. 2009;66:41-8; discussion 48-9.

12. Dente CJ, Shaz BH, Nicholas JM, et al. Improvements in early mortality and coagulopathy are sustained better in patients with blunt trauma after institution of a massive transfusion protocol in a civilian level I trauma center. J Trauma. 2009;66:16161624.

13. Cotton BA, Gunter OL, Isbell J, et al. Damage control hematology: The impact of a trauma exsanguination protocol on survival and blood product utilization. J Trauma. 2008;64:1177-82; discussion 1182-3.

14. Riskin DJ, Tsai TC, Riskin L, et al. Massive transfusion protocols: The role of aggressive resuscitation versus product ratio in mortality reduction. J Am Coll Surg. 2009;209:198-205.

15. Schuster KM, Davis KA, Lui FY, Maerz LL, Kaplan LJ. The status of massive transfusion protocols in united states trauma centers: Massive transfusion or massive confusion? Transfusion. 2010.

16. Schreiber MA, Perkins J, Kiraly L, Underwood S, Wade C, Holcomb JB. Early predictors of massive transfusion in combat casualties. J Am Coll Surg. 2007;205:541545.

17. McLaughlin DF, Niles SE, Salinas J, et al. A predictive model for massive transfusion in combat casualty patients. J Trauma. 2008;64:S57-63; discussion S63. 
18. Cancio LC, Wade CE, West SA, Holcomb JB. Prediction of mortality and of the need for massive transfusion in casualties arriving at combat support hospitals in iraq. $J$ Trauma. 2008;64:S51-5; discussion S55-6.

19. Nunez TC, Voskresensky IV, Dossett LA, Shinall R, Dutton WD, Cotton BA. Early prediction of massive transfusion in trauma: Simple as ABC (assessment of blood consumption)? J Trauma. 2009;66:346-352.

20. Yucel N, Lefering R, Maegele M, et al. Trauma associated severe hemorrhage (TASH)-score: Probability of mass transfusion as surrogate for life threatening hemorrhage after multiple trauma. J Trauma. 2006;60:1228-36; discussion 1236-7.

21. Inaba K, Teixeira PG, Shulman I, et al. The impact of uncross-matched blood transfusion on the need for massive transfusion and mortality: Analysis of 5,166 uncrossmatched units. J Trauma. 2008;65:1222-1226.

22. Kaufmann CR, Dwyer KM, Crews JD, Dols SJ, Trask AL. Usefulness of thrombelastography in assessment of trauma patient coagulation. J Trauma. 1997;42:71620; discussion 720-2.

23. Plotkin AJ, Wade CE, Jenkins DH, et al. A reduction in clot formation rate and strength assessed by thrombelastography is indicative of transfusion requirements in patients with penetrating injuries. $J$ Trauma. 2008;64:S64-8.

24. Carroll RC, Craft RM, Langdon RJ, et al. Early evaluation of acute traumatic coagulopathy by thrombelastography. Transl Res. 2009;154:34-39.

25. Luddington RJ. Thrombelastography/thromboelastometry. Clin Lab Haematol. 2005;27:81-90.

26. Hett DA, Walker D, Pilkington SN, Smith DC. Sonoclot analysis. Br J Anaesth. 1995;75:771-776. 
27. Ganter MT, Hofer CK. Coagulation monitoring: Current techniques and clinical use of viscoelastic point-of-care coagulation devices. Anesth Analg. 2008;106:1366-1375.

28. Shore-Lesserson L, Manspeizer HE, DePerio M, Francis S, Vela-Cantos F, Ergin MA. Thromboelastography-guided transfusion algorithm reduces transfusions in complex cardiac surgery. Anesth Analg. 1999;88:312-319.

29. Spalding GJ, Hartrumpf M, Sierig T, Oesberg N, Kirschke CG, Albes JM. Cost reduction of perioperative coagulation management in cardiac surgery: Value of "bedside" thrombelastography (ROTEM). Eur J Cardiothorac Surg. 2007;31:1052-1057.

30. Coakley M, Reddy K, Mackie I, Mallett S. Transfusion triggers in orthotopic liver transplantation: A comparison of the thromboelastometry analyzer, the thromboelastogram, and conventional coagulation tests. J Cardiothorac Vasc Anesth. 2006;20:548-553.

31. Kang Y. Coagulation and liver transplantation. Transplant Proc. 1993;25:2001-2005.

32. Lang T, Bauters A, Braun SL, et al. Multi-centre investigation on reference ranges for ROTEM thromboelastometry. Blood Coagul Fibrinolysis. 2005;16:301-310.

33. Johansson PI, Stensballe J. Effect of haemostatic control resuscitation on mortality in massively bleeding patients: A before and after study. Vox Sang. 2009;96:111-118.

34. Martini WZ, Cortez DS, Dubick MA, Park MS, Holcomb JB. Thrombelastography is better than PT, aPTT, and activated clotting time in detecting clinically relevant clotting abnormalities after hypothermia, hemorrhagic shock and resuscitation in pigs. J Trauma. 2008;65:535-543.

35. Jeger V, Zimmermann H, Exadaktylos AK. Can RapidTEG accelerate the search for coagulopathies in the patient with multiple injuries? J Trauma. 2009;66:1253-1257. 
36. Brenni M, Worn M, Bruesch M, Spahn DR, Ganter MT. Successful rotational thromboelastometry-guided treatment of traumatic haemorrhage, hyperfibrinolysis and coagulopathy. Acta Anaesthesiol Scand. 2010;54:111-117.

37. Talving P, Benfield R, Hadjizacharia P, Inaba K, Chan LS, Demetriades D. Coagulopathy in severe traumatic brain injury: A prospective study. $J$ Trauma. 2009;66:55-61; discussion 61-2.

38. Wafaisade A, Lefering R, Tjardes T, et al. Acute coagulopathy in isolated blunt traumatic brain injury. Neurocrit Care. 2010;12:211-219.

39. Stein SC, Smith DH. Coagulopathy in traumatic brain injury. Neurocrit Care. 2004;1:479-488. 
Table 1. Demographic and Clinical Injury Characteristics Comparing the Massive and Non-Massive Transfusion Group

\begin{tabular}{|c|c|c|c|c|}
\hline & $\begin{array}{l}\text { All Patients } \\
\quad(n=53)\end{array}$ & $\begin{array}{c}\text { MT } \\
(n=18)\end{array}$ & $\begin{array}{c}\text { Non-MT } \\
(\mathbf{n}=35)\end{array}$ & $p$ Value \\
\hline Age (years), mean \pm SEM & $39.6 \pm 2.5$ & $42.1 \pm 4.2$ & $38.3 \pm 3.1$ & 0.447 \\
\hline Age $\geq 55$ years & $22.6 \%(12 / 53)$ & $27.8 \%(5 / 18)$ & $20.0 \%(7 / 35)$ & 0.730 \\
\hline Male & $75.5 \%(40 / 53)$ & $61.1 \%(11 / 18)$ & $82.9 \%(29 / 35)$ & 0.101 \\
\hline $\mathrm{GCS} \leq 8$ & $78.8 \%(41 / 52)$ & $76.5 \%(13 / 17)$ & $80.0 \%(28 / 35)$ & 1.000 \\
\hline $\mathrm{SBP}<90 \mathrm{mmHg}$ & $19.2 \%(10 / 52)$ & $35.3 \%(6 / 17)$ & $11.4 \%(4 / 35)$ & 0.062 \\
\hline Heart rate $>110 /$ min & $15.4 \%(8 / 52)$ & $17.6 \%(3 / 17)$ & $14.3 \%(5 / 35)$ & 1.000 \\
\hline ISS, mean \pm SEM & $31.1 \pm 1.7$ & $37.1 \pm 3.2$ & $28.0 \pm 1.8$ & 0.012 \\
\hline ISS $\geq 25$ & $66.0 \%(35 / 53)$ & $77.8 \%(14 / 18)$ & $60.0 \%(21 / 35)$ & 0.196 \\
\hline Head AIS $\geq 3$ & $64.2 \%(34 / 53)$ & $50.0 \%(9 / 18)$ & $71.4 \%(25 / 35)$ & 0.123 \\
\hline Chest AIS $\geq 3$ & $62.3 \%(33 / 53)$ & $66.7 \%(12 / 18)$ & $60.0 \%(21 / 35)$ & 0.635 \\
\hline Abdomen AIS $\geq 3$ & $43.4 \%(23 / 53)$ & $77.8 \%(14 / 18)$ & $25.7 \%(9 / 35)$ & $<0.001$ \\
\hline Extremity AIS $\geq 3$ & $26.4 \%(14 / 53)$ & $44.4 \%(8 / 18)$ & $17.1 \%(6 / 35)$ & 0.049 \\
\hline \multicolumn{5}{|c|}{ Surgical Procedures on Admission } \\
\hline Craniotomy / Craniectomy & $24.5 \%(13 / 53)$ & $22.2 \%(4 / 18)$ & $25.7 \%(9 / 35)$ & 1.000 \\
\hline Thoracotomy / Sternotomy & $11.3 \%(6 / 53)$ & $27.8 \%(5 / 18)$ & $2.9 \%(1 / 35)$ & 0.014 \\
\hline Laparotomy & $15.1 \%(8 / 53)$ & $38.9 \%(7 / 18)$ & $2.9 \%(1 / 35)$ & 0.001 \\
\hline Pelvic Clamp / External Fixator & $9.4 \%(5 / 53)$ & $27.8 \%(5 / 18)$ & $0 \%(0 / 35)$ & 0.003 \\
\hline External Fixator Extremity & $11.3 \%(6 / 53)$ & $22.2 \%(4 / 18)$ & $5.7 \%(2 / 35)$ & 0.164 \\
\hline
\end{tabular}

Abbreviations: MT, Massive Transfusion; GCS, Glasgow Coma Scale; SBP, systolic blood pressure; ISS, Injury Severity Score; SEM, standard error of the mean; AIS, Abbreviated Injury Scale. 
Table 2. Blood Component Summary for Different Time Frames within the First 24 Hours

\begin{tabular}{|c|c|c|c|c|}
\hline & $\begin{array}{c}\text { Total } \\
(n=53)\end{array}$ & $\begin{array}{c}\text { MT } \\
(n=18)\end{array}$ & $\begin{array}{c}\text { Non-MT } \\
(n=35)\end{array}$ & $p$ Value \\
\hline \multicolumn{5}{|l|}{ PRBC (Units) } \\
\hline $0-6 \mathrm{hrs}$ & $6.9 \pm 1.5$ & $17.1 \pm 3.2$ & $1.7 \pm 0.4$ & $<0.001$ \\
\hline $6-12 \mathrm{hrs}$ & $1.4 \pm 0.4$ & $3.1 \pm 1.0$ & $0.5 \pm 0.2$ & 0.002 \\
\hline $12-24 \mathrm{hrs}$ & $1.1 \pm 0.3$ & $2.1 \pm 0.9$ & $0.6 \pm 0.3$ & 0.064 \\
\hline \multicolumn{5}{|l|}{ FFP (Units) } \\
\hline $0-6 \mathrm{hrs}$ & $5.0 \pm 1.0$ & $12.1 \pm 2.2$ & $1.3 \pm 0.3$ & $<0.001$ \\
\hline $6-12 \mathrm{hrs}$ & $1.0 \pm 0.3$ & $2.4 \pm 0.9$ & $0.2 \pm 0.1$ & 0.005 \\
\hline $12-24 \mathrm{hrs}$ & $0.9 \pm 0.3$ & $1.9 \pm 0.8$ & $0.4 \pm 0.2$ & 0.043 \\
\hline \multicolumn{5}{|l|}{ PLT (Units) } \\
\hline $0-6 \mathrm{hrs}$ & $3.2 \pm 0.9$ & $9.0 \pm 2.1$ & $0.3 \pm 0.2$ & $<0.001$ \\
\hline $6-12 \mathrm{hrs}$ & $1.1 \pm 0.5$ & $2.8 \pm 1.3$ & $0.2 \pm 0.2$ & 0.007 \\
\hline $12-24 \mathrm{hrs}$ & $1.1 \pm 0.4$ & $2.4 \pm 1.0$ & $0.3 \pm 0.2$ & 0.009 \\
\hline FFP:PRBC ratio at $24 \mathrm{hrs}$ & $0.49 \pm 0.08$ & $0.76 \pm 0.07$ & $0.35 \pm 0.11$ & $<0.001$ \\
\hline PLT:PRBC ratio at $24 \mathrm{hrs}$ & $0.28 \pm 0.06$ & $0.63 \pm 0.11$ & $0.10 \pm 0.05$ & $<0.001$ \\
\hline
\end{tabular}

Values are expressed as Mean \pm SEM

Abbreviations: MT, Massive Transfusion; PRBC, Packed Red Blood Cells; FFP, Fresh Frozen Plasma; PLT, Platelets; SEM, Standard Error of the Mean 
Table 3. Admission Laboratory Values Comparing the Massive and Non-Massive Transfusion Group

\begin{tabular}{lcccc}
\hline & $\begin{array}{c}\text { All Patients } \\
(\mathbf{n = 5 3})\end{array}$ & $\begin{array}{c}\text { MT } \\
(\mathbf{n = 1 8})\end{array}$ & $\begin{array}{c}\text { Non-MT } \\
(\mathbf{n = 3 5})\end{array}$ & $\boldsymbol{p}$ Value \\
\hline Hemoglobin (g/dL) & $10.2 \pm 0.4$ & $7.9 \pm 0.4$ & $11.4 \pm 0.4$ & $<0.001$ \\
Hematocrit (\%) & $31.5 \pm 1.2$ & $24.2 \pm 1.3$ & $35.1 \pm 1.2$ & $<0.001$ \\
Lactate (mmol/L) & $3.6 \pm 0.4$ & $4.8 \pm 0.8$ & $3.0 \pm 0.3$ & 0.056 \\
Base Deficit (mmol/L) & $4.4 \pm 0.6$ & $5.9 \pm 1.1$ & $3.6 \pm 0.6$ & 0.052 \\
pH & $7.29 \pm 0.02$ & $7.24 \pm 0.04$ & $7.31 \pm 0.01$ & 0.301 \\
\hline INR & $1.30 \pm 0.04$ & $1.46 \pm 0.07$ & $1.22 \pm 0.05$ & 0.001 \\
PTT (sec) & $34.1 \pm 2.2$ & $42.4 \pm 5.0$ & $29.7 \pm 1.8$ & $<0.001$ \\
PLT $\left(\mathrm{x} 10^{3}\right)$ & $170.0 \pm 8.4$ & $147.9 \pm 17.4$ & $181.4 \pm 8.7$ & 0.074 \\
\hline
\end{tabular}

Values are expressed as Mean \pm SEM

Abbreviations: MT, Massive Transfusion; SEM, Standard Error of the Mean; INR, International Normalized Ratio; PTT, Prothrombin Time; PLT, Platelets 
Table 4. Rotation Thromboelastography Parameters in the Massive and Non-Massive Transfusion Group

\begin{tabular}{lccccc}
\hline & $\begin{array}{c}\text { Normal } \\
\text { Ranges }^{32}\end{array}$ & $\begin{array}{c}\text { All Patients } \\
(\mathbf{n = 5 3})\end{array}$ & $\begin{array}{c}\text { MT } \\
(\mathbf{n = 1 8})\end{array}$ & $\begin{array}{c}\text { Non-MT } \\
(\mathbf{n = 3 5})\end{array}$ & $\boldsymbol{p}$ Value \\
\hline $\boldsymbol{E X T E M}$ & & & & & \\
CT $(\mathrm{sec})$ & $38-79$ & $115.8 \pm 11.1$ & $107.9 \pm 10.1$ & $120.0 \pm 16.2$ & 0.583 \\
CFT $(\mathrm{sec})$ & $34-159$ & $284.0 \pm 52.0$ & $434.2 \pm 136.7$ & $201.7 \pm 21.5$ & 0.009 \\
$\alpha$ angle & $63-83$ & $54.2 \pm 2.0$ & $49.8 \pm 2.5$ & $56.6 \pm 2.6$ & 0.044 \\
A10 (mm) & $43-65$ & $34.7 \pm 1.9$ & $29.9 \pm 2.4$ & $37.2 \pm 2.5$ & 0.032 \\
A20 (mm) & $50-71$ & $41.3 \pm 2.1$ & $36.9 \pm 3.0$ & $43.6 \pm 2.7$ & 0.054 \\
A30 (mm) & $50-69$ & $43.8 \pm 2.1$ & $38.6 \pm 3.6$ & $46.3 \pm 2.4$ & 0.051 \\
MCF (mm) & $50-72$ & $43.4 \pm 2.0$ & $39.3 \pm 2.7$ & $45.5 \pm 2.6$ & 0.041 \\
\hline INTEM & & & & & 0.050 \\
CT $(\mathrm{sec})$ & $100-240$ & $239.7 \pm 32.7$ & $232.2 \pm 19.2$ & $243.3 \pm 48.0$ & 0.001 \\
CFT $(\mathrm{sec})$ & $30-110$ & $267.9 \pm 56.1$ & $471.3 \pm 169.9$ & $178.1 \pm 19.9$ & 0.001 \\
$\alpha$ angle & $70-83$ & $57.4 \pm 1.9$ & $48.5 \pm 3.2$ & $61.9 \pm 2.0$ & $<0.001$ \\
A10 (mm) & $44-66$ & $36.8 \pm 1.6$ & $28.6 \pm 2.4$ & $40.9 \pm 1.7$ & 0.001 \\
A20 (mm) & $50-71$ & $44.3 \pm 1.7$ & $35.7 \pm 3.3$ & $48.3 \pm 1.6$ & 0.002 \\
A30 (mm) & $57-72$ & $46.9 \pm 1.5$ & $39.8 \pm 2.7$ & $50.0 \pm 1.5$ & $<0.001$ \\
MCF (mm) & $50-72$ & $46.3 \pm 1.6$ & $37.5 \pm 2.9$ & $50.7 \pm 1.4$ & \\
\hline
\end{tabular}

Values are expressed as Mean \pm SEM

Abbreviations: MT, Massive Transfusion; CT, Clotting Time; CFT, Clot Formation Time; A10/20/30, Clot Firmness 10/20/30 Minutes after CT; MCF, Maximum Clot Firmness 
Table 5. Independent Risk Factors for Massive Transfusion in Severely Injured Trauma Patients

\begin{tabular}{ccccc}
\hline Step & Variable & Adjusted Odds Ratio (95\% CI) & Adjusted $\boldsymbol{p}$ Value & $\mathbf{R}^{\mathbf{2}}$ \\
\hline 1 & Hemoglobin $\leq 10 \mathrm{~g} / \mathrm{dL}$ & $18.18(2.73-125.00)$ & 0.003 & 0.350 \\
2 & Abnormal INTEM MCF & $8.47(1.19-62.50)$ & 0.033 & 0.135 \\
\hline
\end{tabular}

Risk factors entered into the model $(p<0.2)$ : Systolic blood pressure $<90 \mathrm{mmHg}$ vs. $\geq 90 \mathrm{mmHg}$; hemoglobin $\leq 10 \mathrm{~g} / \mathrm{dL}$ vs. $>10$ $\mathrm{g} / \mathrm{dL}$; Base Deficit $\leq 6 \mathrm{mmol} / \mathrm{L}$ vs. $>6 \mathrm{mmol} / \mathrm{L} ;$ INR $>1.2 \mathrm{vs} . \leq 1.2 ;$ PTT $>36 \mathrm{sec}$ vs. $\leq 36 \mathrm{sec}$; Platelet count $<100 \mathrm{vs}$. $\geq 100$; Abnormal vs. Normal EXTEM: CFT, alpha angel, A10, A20, A30, MCF; Abnormal vs. Normal INTEM: alpha angel, A10, A20, A30, MCF

Abbreviations: CI, Confidence Interval; MCF, Maximum Clot Firmness; INR, International Normalized Ratio; PTT, Partial Thromboplastin Time; CFT, Clot Formation Time; A10/20, Clot Firmness x Minutes after CT 
Figure 1. Risk for Massive Transfusion by Risk Factors $(p<0.2)$

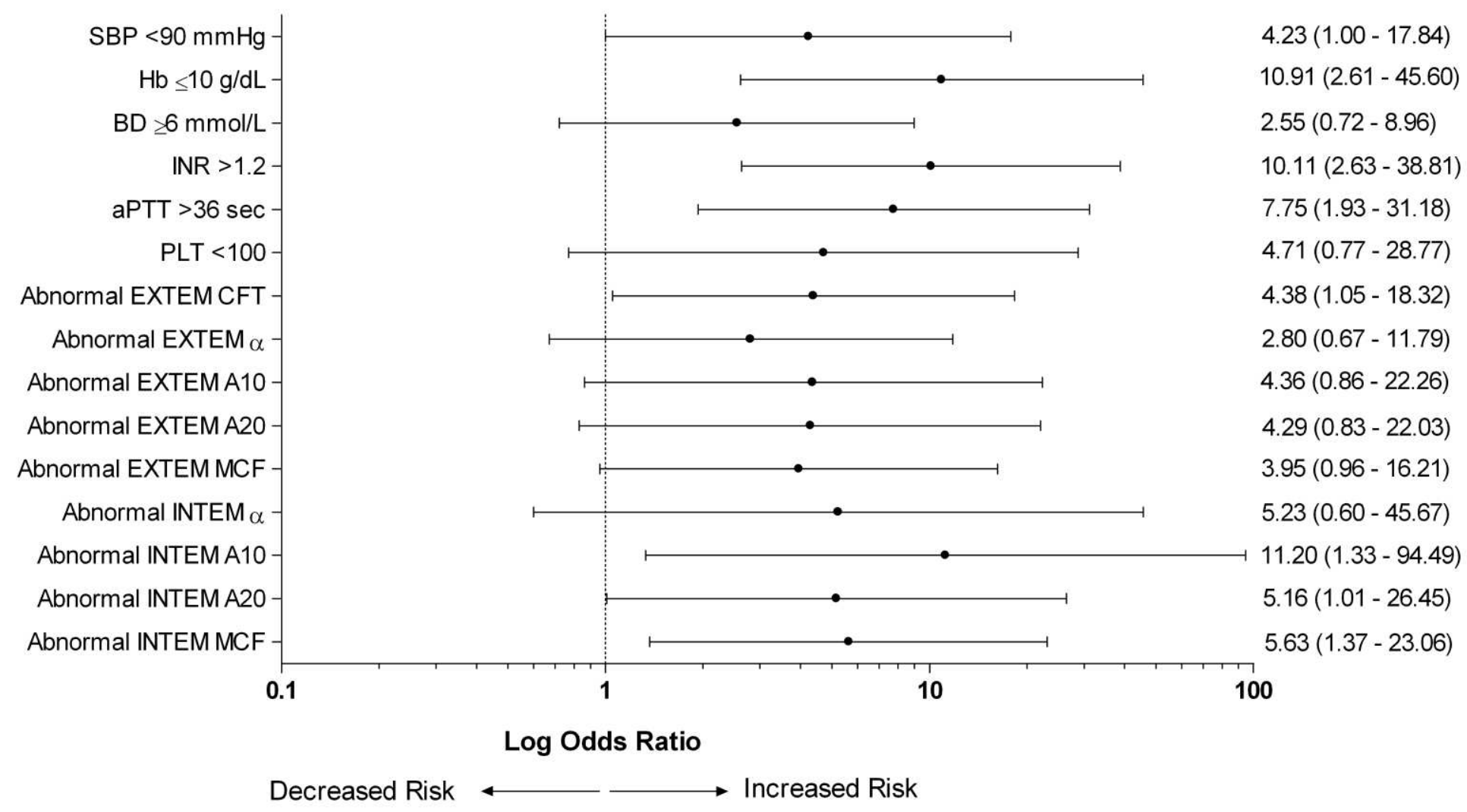

Abbreviations: SBP, Systolic Blood Pressure; Hb, Hemoglobin; BD, Base Deficit; INR, International Normalized Ratio; aPTT, Activated Partial Thromoplastin Time; PLT, Platelets; CFT, Clot Formation Time; A10/20, Clot Amplitude at 10/20 Minutes; MCF, Maximum Clot Firmness 